\title{
Calculation of reinforced Concrete Beams
}

\author{
Smirnova Zhanna. ${ }^{1}$, Vaganova O.I. ${ }^{2}$, Cherney O.T. ${ }^{3}$, Kutepova L.I. ${ }^{4}$ \\ ${ }^{1}$ Minin Nizhny Novgorod State Pedagogical University, Nizhny Novgorod, Russian Federation \\ z.v.smirnova@mininuniver.ru \\ ${ }^{2}$ Minin Nizhny Novgorod State Pedagogical University (Minin University), Nizhny Novgorod, Russian \\ Federation, vaganova_o@mail.ru \\ ${ }^{3}$ Minin Nizhny Novgorod State Pedagogical University (Minin University), Nizhny Novgorod, Russian Federation, \\ fiolet1975@mail.ru \\ ${ }^{4}$ Minin Nizhny Novgorod State Pedagogical University (Minin University), Nizhny Novgorod, Russian Federation, \\ lubovkutepova@mail.ru
}

\begin{abstract}
The construction industry, as one of the most important for people's lives, ensuring the viability and development of cities and towns, among the main structural materials, uses well-known reinforced concrete. Being the basis of industrial, hydraulic engineering, housing, heat power, transport and agricultural construction, reinforced concrete has established itself as a reliable and efficient material. In this work, the calculation of reinforced concrete blocks. The nature of the work of a concrete beam is considered. The prerequisites for calculating reinforced concrete elements are highlighted. The advantages and disadvantages of reinforced concrete are determined.
\end{abstract}

Key words: reinforced concrete, beam analysis, reinforcement of reinforced concrete beam

\section{INTRODUCTION}

The construction industry, as one of the most important for people's lives, ensuring the viability and development of cities and towns, among the main structural materials, uses well-known reinforced concrete. Being the basis of industrial, hydraulic engineering, housing, heat power, transport and agricultural construction, reinforced concrete has established itself as a reliable and efficient material.

Having a number of specific qualities, reinforced concrete should be used taking into account a number of provisions. When designing buildings and structures, the structures of which are supposed to be made of reinforced concrete, first of all, it is necessary to ensure their reliability, which is achieved by observing the requirements of existing standards.

A knowledge of the rules and rules for calculating reinforced concrete building structures will make it possible to create not only reliable and cost-effective structures, but also structures unique in their architecture [3].

The created base of scientific research of reinforced concrete in the middle of the 19th century made it possible to create the theoretical foundations for calculating reinforced concrete and the basic principles of its design. Significant contribution to this was made by the researchers Consider, Genebeck (France), Kenen, Mersch (Germany) and others.

In Russia, the scientific base for the study of reinforced concrete developed on the basis of foreign experience and our own practice. It is worth noting the importance of the tests of Professor N.A. Beleubsky. In 1891, he was the first to conduct a series of tests of reinforced concrete structures: slabs, beams, arches, tanks, grain silos, a bridge span of 17 meters.

In 1895, A.F. Loleit spoke at the 2nd Congress of Architects in Russia, who subsequently created the basic principles of the modern theory of reinforced concrete. In 1899, reinforced concrete was officially allowed in Russia [1].

The development of the theory of reinforced concrete in Russia in the first half of the 19th century is also associated with the names of A. A. Gvozdev, V. V. Mikhailov, M. S. Borishansky, A. P. Vasiliev, V. I. Murashev, P. L. Pasternak, Ya. V. Stolyarova, O. Ya. Berg and others.

In 1904, in the city of Nikolaev, according to the project of engineers N. Pyatnitsky and A. Baryshnikov, the world's first marine lighthouse was made of reinforced concrete 36 meters high with walls $10 \mathrm{~cm}$ thick at the top and $20 \mathrm{~cm}$ lower. This lighthouse was at that time the largest reinforced concrete structure in the world [2].

The use in the construction of frame and thin-walled spatial systems using their rigidity and solidity should be considered the second stage in the development of reinforced concrete.

\section{LITERATURE REVIEW}

Reinforced concrete is called a building material, in which concrete and steel reinforcement are connected in a monolithic whole. The purpose of using these two materials is that concrete accepts compressive loads well and tensile steel. Therefore, performing certain structures of reinforced concrete in the area that will be subject to stretching, reinforcement is introduced to prevent the destruction of the element. 


\subsection{Prerequisites for the calculation of reinforced concrete elements}

Concrete, being an artificial stone, resists stretching 10-15 times weaker than compression, which limits the possibility of its use (from significant loads, rapid destruction occurs), or necessitates an increase in the size of the element, which is uneconomical and due to a number of structural requirements for buildings it is not profitable. The nature of the concrete element and the nature of its destruction are shown in Figure 1.

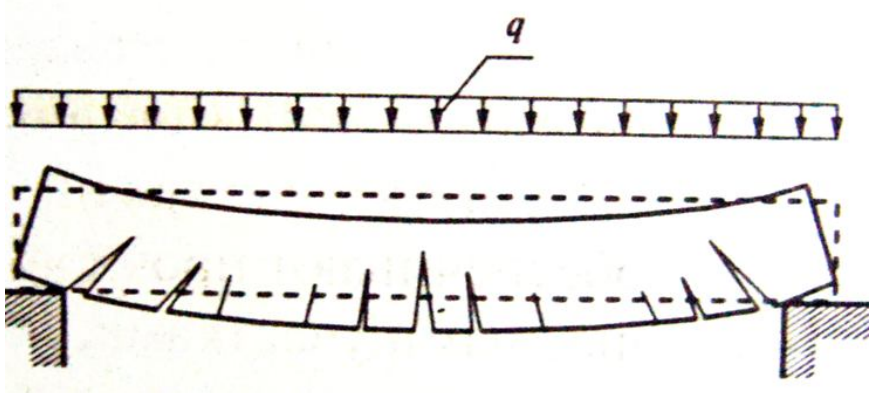

Figure 1: The nature of the concrete beam

However, if a small amount of steel is added to the stretched zone of the concrete element (1-2\% of the cross-sectional area), then its bearing capacity will significantly increase (10-20 times) [4,5].Although they can also use reinforcement to reinforce concrete in a compressed area. Thus, placing the reinforcement in the "dangerous" zone of the element can prevent the occurrence of destructive cracks Figure 2.

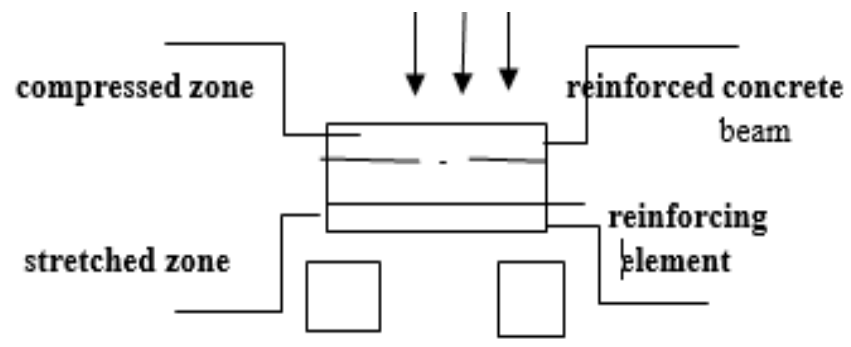

Figure 2: Reinforcement of reinforced concrete beams in the stretched zone.

However, an excessive amount of reinforcement in the element can be dangerous, since stresses from the reinforcement can cause deformations and damage. Therefore, to obtain a reliable and durable reinforced concrete element, it is necessary to follow the rules of calculation and construction of reinforced concrete elements [6].

The breadth of the use of reinforced concrete is justified by its advantages. However, as a structural material, it also has some disadvantages.

Table 1: Advantages and disadvantages of reinforced concrete

\begin{tabular}{|l|l|}
\hline \multicolumn{1}{|c|}{ Benefits of Reinforced Concrete } & \multicolumn{1}{|c|}{$\begin{array}{c}\text { The disadvantages of reinforced } \\
\text { concrete }\end{array}$} \\
\hline $\begin{array}{l}\text { 1) Advantageous physical and mechanical properties (has significant resistance to } \\
\text { static and dynamic loads) }\end{array}$ & 1) Significant mass of structures \\
2) Seismic and vibration resistance & 2) Increased heat and sound conductivity \\
3) Durability & 3) The complexity of the work \\
4) Good weather resistance & The need for specialized personnel and \\
5) Fire resistance & \\
6) Consists of widespread materials & \\
7) Malleable in terms of shaping (it's easy to give it almost any shape) \\
8) Concrete strength may increase over time & \\
9) Low operating costs & \\
\hline
\end{tabular}

The combined resistance of concrete and steel reinforcement to external loads is determined by an advantageous combination of physical and mechanical properties of these materials:

- during hardening of concrete, significant adhesion forces arise between it and steel reinforcement, as a result of which both materials are deformed together under load in reinforced concrete elements;

- concrete (protective layer of concrete) protects the steel reinforcement enclosed in it from corrosion damage, as well as from direct exposure to fire [7].

The thickness of the protective layer of concrete depends on the type of structure, the conditions of its operation, the purpose and diameter of the reinforcement. The minimum thickness of the protective layer of concrete is taken not less than the diameter of the reinforcement bar. Detailed recommendations in clauses 8.3.1, 8.3.2. SP 52-101-2003.

Relatively high weight of reinforced concrete - quality under certain conditions, it is positive, but in many cases undesirable, therefore, to reduce the mass of structures, less material-intensive structures (thin-walled and hollow) are used, as well as concrete structures on lightweight aggregates.

\section{EXPERIMENTATION}

Beams refer to bending elements subjected to bending moment $(\mathrm{M})$ or bending moment and lateral force $(\mathrm{M}+\mathrm{Q})$. The main flexible elements in the general structure of buildings are slabs and beams. 
Reinforced concrete beams are distinguished by purpose, shape, size and other parameters that are defined in GOST 24893.1-81, GOST 24893.2-81, GOST 20372-90 [8].

The main types of sections of reinforced concrete beams are presented in Figure 3.
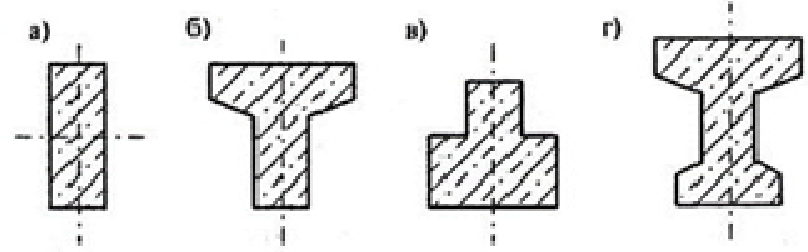

Figure 3: Cross sections of reinforced concrete beams: a) rectangular; b) t-shaped; c) tee with the bottom location of the shelf; d) I-beam.

First of all, beams can be subdivided according to their field of application: foundation, rafters, crane, floor beams and others.

Base beams are used in the construction of foundations of buildings for various purposes, but are used mainly in the construction of frame buildings. The purpose of their device is the installation of external walls on them [12].

The device of foundation beams. To which the load from the walls is transmitted, it is necessary in the following cases:

1) When installing self-supporting brick walls with a thickness of not more than 2 bricks;

2) When installing self-supporting walls of large concrete blocks, $40-50 \mathrm{~cm}$ thick;

3) When installing self-supporting and curtain walls from panels with a thickness of $160,200,240$ and $300 \mathrm{~mm}$.

The cross section of the foundation beams, as a rule, is rectangular, tee or trapezoidal [6].
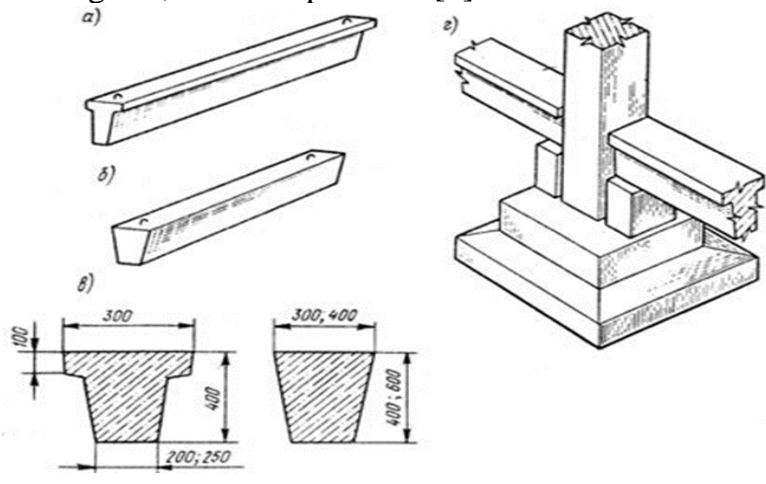

Figure 4: Foundation beams: a) T-section; b) a trapezoidal section; c) the dimensions of the cross sections of the foundation beams; d) the design of the foundation beam device.

For the production of foundation beams, concrete B20-B40 is mainly used $[9,10.13]$.
Crane reinforced concrete beams are designed for the installation of crane tracks on them and the perception of loads from the movement of bridge cranes (with a lifting capacity of up to 30 tons with light and medium duty). They also serve as longitudinal elements of the building frame and provide its spatial rigidity. For their manufacture, high-strength reinforcement and concrete of class B30-B50 are used.Reinforced concrete beams mainly have a T-section with a thickening of the wall on the supports (for $6 \mathrm{~m}$ spans), and I-beams with an asymmetric profile, where the upper shelf is wider than the lower (12 m span).

The upper shelves of the crane beams are used to attach crane rails to them, as well as to absorb the horizontal inertial forces caused by the braking of the crane truck.

The crane path is attached to the crane beams, using bolts, curved hinges and special hooks.

a)

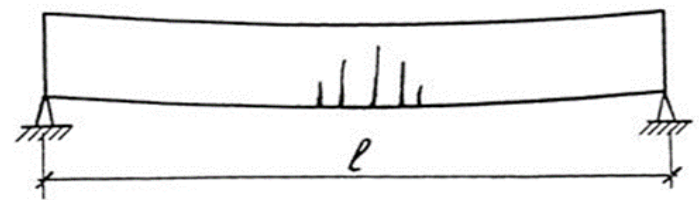

б)

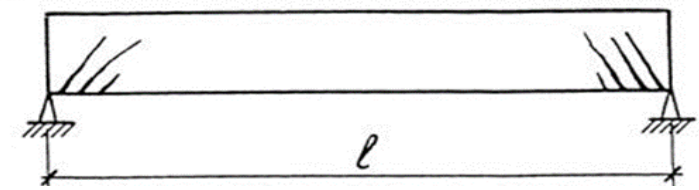

Figure 5: Cracks in a concrete beam: a) normal cracks; b) inclined cracks

In addition, dangerous cracks also appear near the supports (Fig. 5 b). To prevent the destruction of the beam, steel reinforcement is placed in the area where the concrete does not work well (the lower zone is the tensile zone). The normal section (1-1) is perpendicular to the axis of the element and perpendicular to the working reinforcement [11].

Inclined section (2-2) is located at an angle to the axis of the element

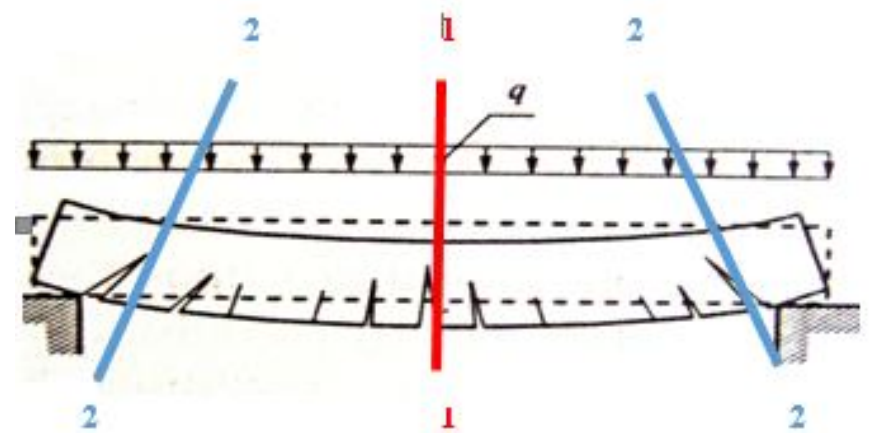

Figure 6: Cracks in a concrete element 


\section{RESULTS AND DISCUSSIONS}

To protect the element from destruction along inclined sections, it is reinforced with special reinforcing products (bends, individual rods, frames), which, like the main working reinforcement, are perpendicular to the axis of the section under consideration. the most dangerous areas in which наклонные трещины - участки вблизи опор $(\approx 1 / 4$ длины балки).

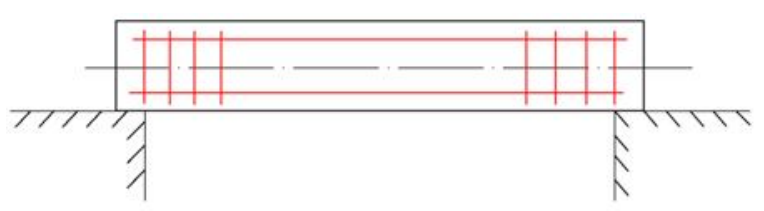

a)

a)

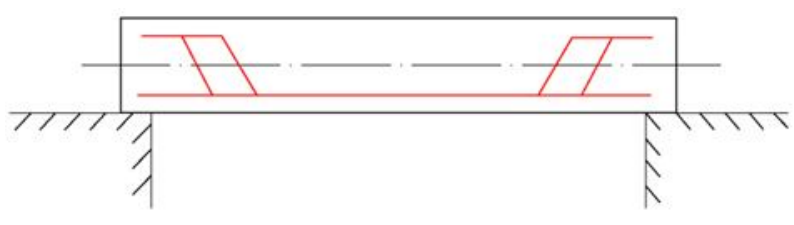

б)

Figure 7: Types of reinforcing elements to protect the beams from normal and inclined cracks: a) reinforcement of the element with vertical rods; b) reinforcement of the element with limbs

The destruction of a reinforced concrete element begins when, in its most dangerous sections, either the concrete reaches its limit values or the reinforcement acquires significant deformations. The destruction begins in sections in which the maximum limit values of the resistance of materials appear. The destruction of an element along inclined and normal sections occurs for various reasons. In a normal section, the structure collapses from the action of a bending moment (M), and in an inclined section from the action of transverse forces $(\mathrm{Q})$ and less often, bending moments (M).

In reinforced concrete "normally" reinforced bending elements, fracture begins with the stretched zone, when the design resistance of the stretched reinforcement reaches its limit. The occurrence of stresses in the compressed zone of concrete and the destruction of its protective layer causes the destruction of the underlying layers and the gradual extension of the longitudinal reinforcement. An increase in the deflection of the element causes cracking of the protective layer of concrete in the stretched zone. [8]. However, if the element is reinforced, then the destruction can begin with the compressed zone of concrete, while the stresses in the stretched reinforcement will be below the limit values, which does not satisfy the requirements for the optimal design of the elements. The destruction of the reinforced concrete element with the harvested zone can occur not only due to incorrect design. The destruction of concrete in the compressed zone also occurs at low temperatures of its heating and significant compressive stresses in it, when the plastic properties of concrete during heating do not have time to manifest themselves and the elastic modulus decreases slightly. This case is similar to the destruction of reinforced reinforced concrete bending elements at ordinary temperature and is characterized by underutilization of the mechanical properties of tensile reinforcement.

\section{CONCLUSION}

Thus, there are two schemes of destruction of reinforced concrete "normally" reinforced flexible elements:

1) when the cause of the loss of strength of the element is the achievement in the tensile reinforcement of the design resistance (Rs) in terms of yield strength;

2) when the strength of the element is exhausted due to the destruction of the compressed zone of concrete earlier than the stresses in the stretched reinforcement, the design resistance is reached.

\section{REFERENCES}

1. Baykov V.N. Sigalov E.E. Reinforced concrete structures: General course Textbook. for the challenge. - 5th ed., Revised. And add. - M.: . Stroyizdat, 1991 .-- 767 p.: Ill.

2. Bondarenko V.M. etc. Calculation of reinforced concrete and stone structures. - M.: Higher School, 1988.

3. GOST 13015.0-2003 Designs and products of concrete and reinforced concrete prefabricated. General technical requirements.

4. GOST 14098-91 Joints for welded reinforcement and embedded products of reinforced concrete structures. Types, designs and sizes.

5. Kiselev NN, Lomunov A.K. Strength analysis of sections of reinforced concrete elements: Methodological instructions. - N. Novgorod: NNGASU, 1999 .-- 44 p.

6. Mandrikov A.P. Examples of the calculation of metal structures. - M .: Stroyizdat, 1991.

7. Popov NN, Zabegaev A.V. Design and calculation of reinforced concrete and stone structures. - $\mathrm{M}$.: Higher school, 2009.

8. Setkov V.N., Serbin E.P. Building constructions: calculation and design: Textbook. - 2nd ed., Ext. and rev. - M .: INFRA - M, 2009 .-- 448 p. - (Secondary vocational education).

9. Barkhatov N.A., Revunov S.E., Mukhina M.V., Gruzdeva M.L., Cherney O.T., Smirnova Z.V. Establishing the orientation of shock wave plane of solar wind magnetic cloud for conclusions about the level of auroral substorm activity JP Journal of Heat and Mass Transfer. 2019. T. 17. № 1. C. 195-202. https://doi.org/10.17654/HM017010195

10. Smirnova Z.V., Rudenko A.A., Vaganova O.I., Cherney O.T., Mokerov D.S., Semakhin E.A. The research of 
Smirnova Zhanna.V et al., International Journal of Emerging Trends in Engineering Research, 8(5), May 2020, 1477 - 1481

carbon construction steel at laser alloying International Journal of Innovative Technology and Exploring Engineering. 2019. T. 8. № 9. C. 2371-2375.

https://doi.org/10.35940/ijitee.I8945.078919

11. Cherney O.T., Zotova V.A., Permovsky A.A., Smirnova Z.V., Vaganova O.I. HYDROGENOUS PHASE Concentration: impact on the structural condition and fracture mechanics of technically pure titanium after different conditions of hydrogenationInternational Journal of Innovative Technology and Exploring Engineering. 2019. T. 8. № 6. C. 535-53।

12. Aaron Don M. Africa, Lourdes Racielle Bulda, Emmanuel Del Rosario, Matthew Zandrick Marasigan, Isabel Navarro Calculating Characteristic Impedance Without Using Symmetricity of Rectangular Coaxial Line. International Journal of Emerging Trends in Engineering Research ( IJETER ) Volume 7, No. 8 August 2019. https://doi.org/10.30534/ijeter/2019/06782019

13. Mohd Fakri Muda, Saffuan Wan Ahmad, Fadhluhartini Muftah , Mohd Syahrul Hisyam Mohd Sani. Mechanical Behaviour of Mortar Made with Washed Bottom Ash as Sand Replacement //International Journal of Emerging Trends in Engineering Research Volume 7, No. 9 September 2019 